\title{
Analysis of Chandigarh Periphery for the Urban Containment
}

\author{
Anuj Sachar, Manish Kaushal, Ashish Kumar, Sandeep Singla
}

\begin{abstract}
The vision of great architect Le Corbusier for an agricultural greenbelt surrounding Chandigarh was to provide an outer beauty by linking rural India to the city. The goal of the greenbelt was to create distinction between rural and urban practices, although it has suffered to restrict expansion and protect functional rural landscape. Today, the symmetry of Chandigarh periphery is destroyed due to rapid urban encroachment and unregulated construction. The present conditions were surveyed, analyzed and solutions were prepared from the assessments of contemporary urban containment practices in the developed countries. All the solution was examined on the basis of their effectiveness. In this case if the assessed solutions are successfully implemented, the desired measures will provide agricultural protection, urban development and rural aspect.
\end{abstract}

\section{Keywords-Periphery, Chandigarh, Urban Containment, Greenbelt and Encroachment.}

\section{INTRODUCTION}

Chandigarh is a city known by the name 'The City Beautiful' and a union territory in India, that serves as the capital of the two neighbouring states Punjab and Haryana. It is one of the early planned cities after the independent and is internationally known for its architecture and urban design. Chandigarh is located near the foothills of the Shivalik range of the Himalayas in northwest India. It covers an area of approximately $114 \mathrm{~km}^{2}$. The city has one of the highest per capita income in the country. Due to economic opportunities, large amount of rural population is entering the city in the search of jobs. Thus, causing increase in population around the outer edges of the city in a chaotic way. The vision of Le Corbusier for an agricultural greenbelt surrounding Chandigarh is far away from contemporary urban containment practices. The outer region suffered to resist urban encroachment and protect functional rural landscape [1]. The study acts as a policy recommendation for monitoring the advancement of Chandigarh periphery. The main aim is to preserve the rural area to a large extent. The present conditions were surveyed, analyzed and solutions were prepared from the assessments of historical and contemporary urban containment practices in the developed countries. All the solution was examined on the basis of their effectiveness. In this case if the assessed solutions are successfully implemented, the desired measures will provide agricultural protection, urban development and rural aspect.

Revised Manuscript Received on July 22, 2019. Anuj Sachar, Civil Engineering, RIMT University, Punjab, India Manish Kaushal, Civil Engineering, RIMT University, Punjab, India Ashish Kumar, Civil Engineering, RIMT University, Punjab, India Sandeep Singla, Civil Engineering, RIMT University, Punjab, India

\section{LITERATURE REVIEW}

The case of Chandigarh and Pacific Northwest; Oregon and Washington are arranged inside the more broad setting of existing writing on the history, hypothesis and contemporary routine with regards to urban regulation. The movement of Garden City is presented as the foundation of twentieth century contemplating urban control. Garden City: the greenbelt technique kept the Garden City from ending up simply one more suburb by constraining its development and preventing sprawl. The Garden City idea in this way turned into a development that remained for the more agreeable adjust of town and country [2]. Raymond Unwin had perceived the criticalness of the Garden City idea and supported the requirement The for particular, independent city around 1901 [3].

Pacific Northwest; Oregon and Washington: Accomplishment of a program is the consequence of the organizers, legislators and administrators that have deliberately customized urban regulation arrangement to address nearby issues. But state directive approach is the most legitimately solid approach to advance a successful development administration program [4].

Pacific Northwest state growth management: One preferred standpoint to state development administration programs is that they can require all networks inside state lines to embrace development administration rehearses [5]. Oregon isn't the principal state to institute a development administration program, however it is maybe the best known case with Washington taking its motivation subsequently. Oregon revolves around modifying typical resource conservation and urban progression, while Washington tries to better oversee and redistribute developments [6]

Chandigarh: There exists a considerable amount of historical and critical literature on the urban core of Chandigarh.[7] But, there exists comparatively little literature on the Periphery Control Area[8]. Urban containment policy alone does not support the type of development within and around the periphery, it need to be enhanced with additional strategies. Suggestions were formed for the province of Punjab and the fringe dependent on exercises gained from the verifiable and contemporary routine with regards to urban regulation, especially inside the PNW [9].

\section{FIELD WORK}

Field work was led by mapping a course to be driven all through the periphery control area. The course was mapped by surveying memorable and contemporary maps from 2003 to 2018 and concentrating on certain location of remarkable advancement and land utilization. Survey was done by taking photograph, documentation, aerial maps, note taking and interviews. The main concentration was on photographic and interview details of the identified destinations of noteworthy change, yet in addition on setting up a

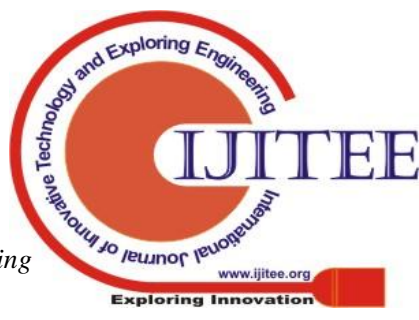


gathering of pictures that precisely spoke to the assortment of land uses and exercises that exist all through the Periphery. Interviews session comprised of discussions regarding the work in progress and the current and previous land uses all through the Periphery with individuals of four different categories including farmers, resident of nearby villages, road users and residents of Chandigarh. A total of 200 respondents were selected for interview using random sampling. The perceptions have been comprehensively sorted to analyse the different conditions and exercises through proper survey work from different classes of people around or in the periphery of the city. Following are the factor considered during the interview sessions:

1. Natural regions preserved

2. Agricultural and related rural uses

3. Land value

4. Unregulated construction

5. Advancement and related urban employments

The above five factors basically highlights the greater part of land utilization that were dominating inside and around the Periphery at the period of field work. Data was collected on the basis of interview session with different category of people in or around the periphery. Total number of respondents of different categories is shown in table 1 .

Table 1. Total numbers of respondents of different category during survey

\begin{tabular}{|c|c|c|}
\hline $\begin{array}{l}\text { S. } \\
\text { No }\end{array}$ & Category of Respondent & $\begin{array}{c}\text { Number of } \\
\text { Respondents }\end{array}$ \\
\hline 1 & Farmers & 50 \\
\hline 2 & $\begin{array}{l}\text { Resident of nearby } \\
\text { villages }\end{array}$ & 50 \\
\hline 3 & Road users & 50 \\
\hline 4 & Residents of Chandigarh & 50 \\
\hline
\end{tabular}

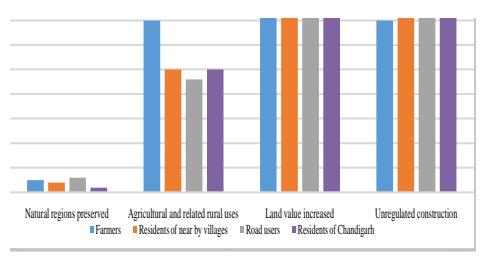

Fig.1 Respond of different category of people for the considered factors As Fig. 1 shows the respond of different category of people in percentage on above mentioned factors. Among all the respondents the value of land has in increased significantly within 15-20 years in or around the periphery of Chandigarh. Similar opinion was noticed about unregulated encroachment and construction. Locals were large in number to respond against the unregulated activities around the periphery. Whereas, the preservation of natural region had suffered badly because of flaws in policies of periphery control act. There were similar response about the advancement and related urban employment among all category of people.
1. Natural Region Preserved: The agricultural land around the periphery and forest area situated at the foot of shivalik hills is shrinking due to unregulated activities. The Sukhna Choe was dammed to make Sukhna Lake (Fig.2), while at the same time it does not fill in as repository, but provides a mainstream entertainment and recreation goal. The Sukhna lake has confronted the issue of high siltation because of soil disintegration of the debasing Shivalik Hills inside the catchment territory. An investigation uncovered that the most astounding rate of siltation was occurring in the town of Sukhomajri, situated on the northeastern side of the Hills. Sukhomajri, initially a peaceful network, enabled their dairy cattle to nibble in the Shivalik Hills. This added to insecure soils and expanded siltation.

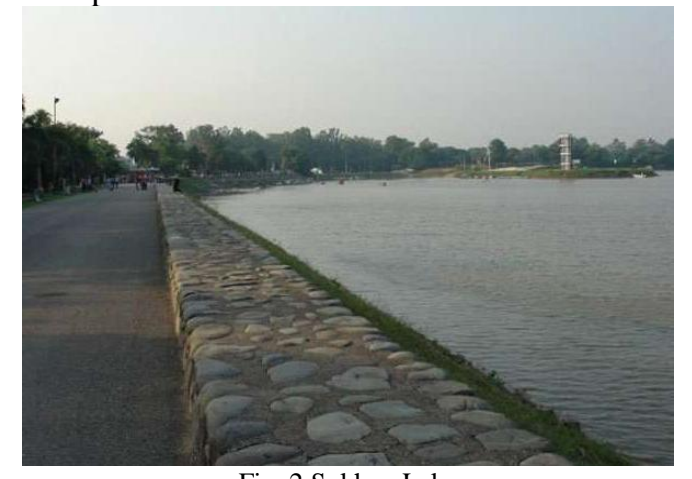

Fig. 2 Sukhna Lake

2. Agricultural and Rural Uses: The number of exercises identified with cultivating, and horticultural generation and preparing were seen along the generally very much trafficked course of field work. Closeness of domesticated animals inside villages and on farming grounds. Jaggery production from the cane juice, was one case on site observation. The task comprises of sugar cane, either reaped nearby or close-by, which is pressed to separate the fluid; the stick juice goes into a pot that is warmed over a fire sustained with the dry mash of the sugar stick. The jaggery is accessible for buy along the roadside (Fig. 3).

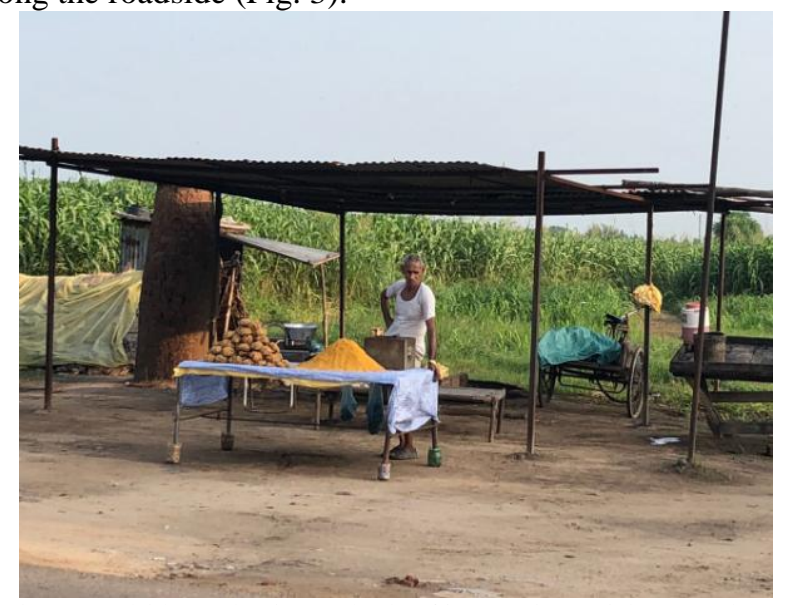

Fig. 3 Roadside production and sale of jaggery in Punjab, near Kharar

3. Land value: The land prices around the periphery of Chandigarh has skyrocketed in past 15 years. The reason behind the rise in prices is due to the demand of land for residential and commercial purposes. Unregulated Construction: Sprawling of village was point of scene all through the Periphery, however it was especially obvious in Naya Gaon. This type of new village 
advancement glaring difference a conspicuous difference to new ace arranged improvements. Rural development proceeds with the current "natural" (i.e. spontaneous) rural development examples and uses locally accessible building materials like block (Figure 4).

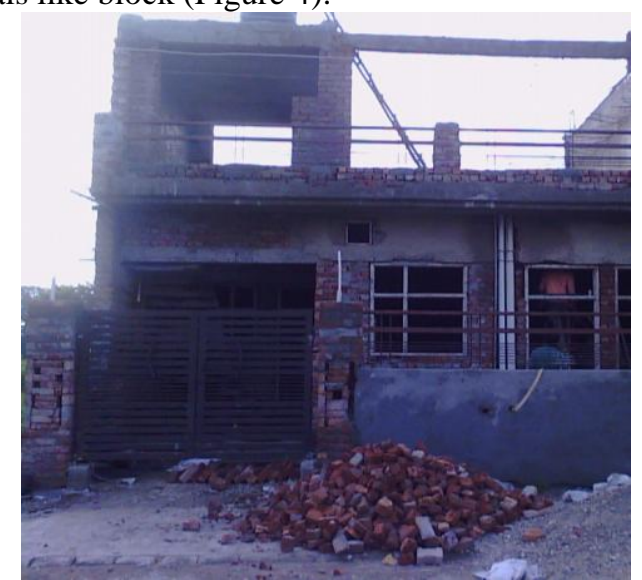

Figure 4: New residential construction north of Naya Gaon

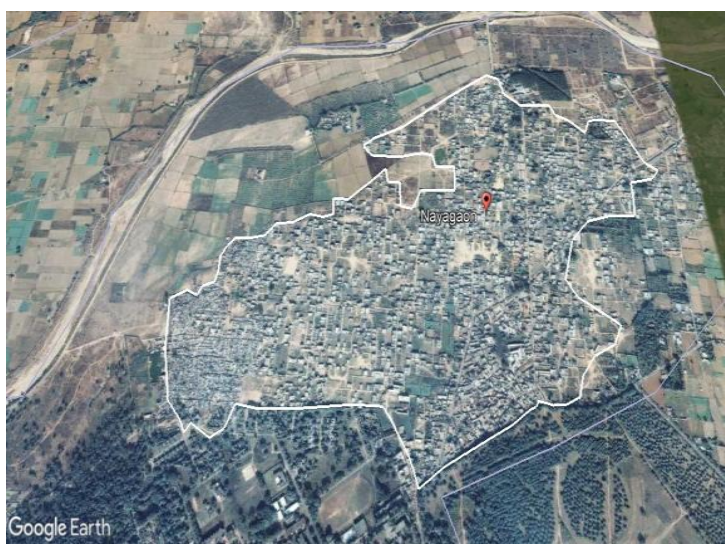

Map 1: 2003 aerial image of Naya Gaon growth and village sprawl, white line represents village construction (Google Earth 2018)

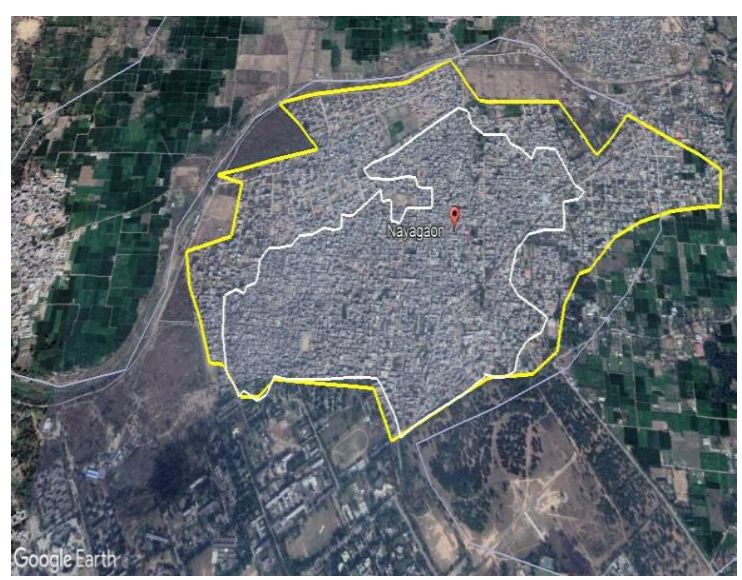

Map 2: 2018 aerial image of Naya Gaon growth and village sprawl beyond the zone of 2003 village construction (Google Earth 2018) 4. Advancement and related urban employments: Unapproved advancement started rising in light of the quick development and interest for administrations, and in 1998 the Punjab Government allowed the regularization of all unlawful development. This pattern of advancements has developed in the course of the most recent decade. Newly constructed houses remain vacant near Kharar Landra road (Fig. 5). The Greater Mohali area in Punjab is planned as financial hubs thereby increases employment opportunities.

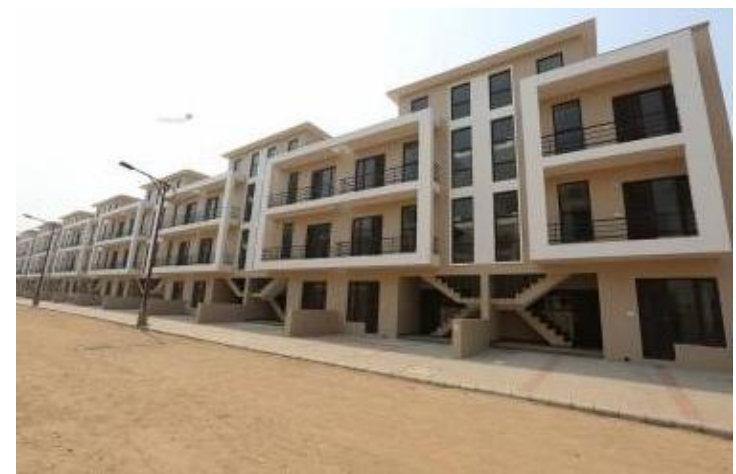

Fig. 5 Newly constructed vacant residential development on Kharar- Landra road

The Mullanpur Master Plan joins existing common towns into its organization, while in the meantime the including agricultural land is picked up and changed over into urban livelihoods (Map 3 and 4). GMADA is locked in with a couple of open private associations in association with the Mullanpur Master Plan, one of which is the Eco City private progression. [11]

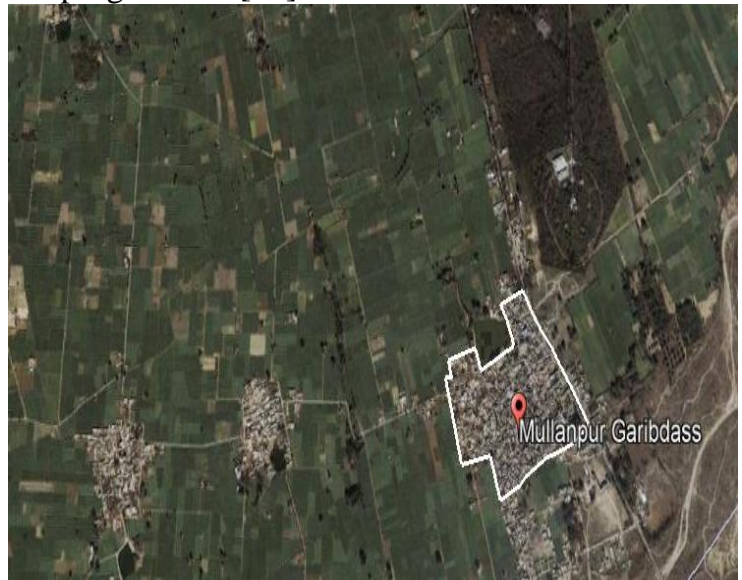

Map 3: 2003 aerial image depicting Village of Mullanpur and active agricultural landscape (Google Earth 2018)

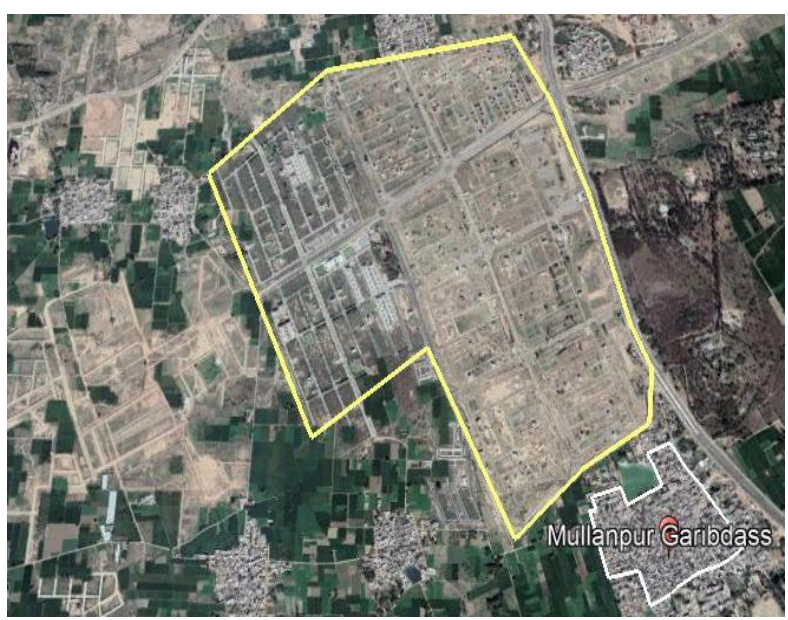

Map 4: 2018 aerial image depicting Village of Mullanpur and encroaching Eco City development (Google Earth 2018)

\section{IV.POLICY RECOMMENDATION}

Different approaches were considered to control the advancement of the periphery of Chandigarh. Out of which two were found to be satisfactory. Approach 1 is state wise approach, where

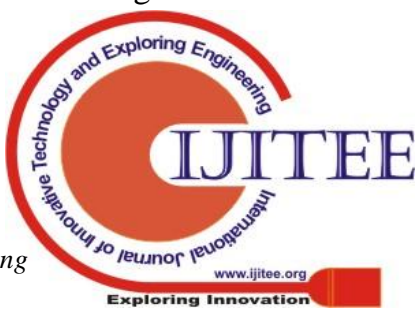


state monitored measures are followed up to establish effective planning to save agricultural area and to contain urban development. Punjab and Haryana hold critical interests in statewide farming action, they get little profit by limiting urban development in the Periphery. On the other side, they stand more to profit by urban advancement because of the financial opportunities due to nearness to Chandigarh. This situation is cleared by the investigation of state development administration programs in the Pacific Northwest. Approach 2 is the expansion of Chandigarh approach, where the central government would reconsider the boundary of Union Territory and make necessary amendments in periphery control act. The fundamental goal of this approach is to recuperate provincial land inside the Periphery from Punjab and Haryana, and reestablish the vision of its planner to have working rural scene inside a greenbelt.

Table 2: Evaluation of objectives on the basis of approaches

\begin{tabular}{|c|c|c|}
\hline Goals & Approach 1 & Approach 2 \\
\hline Urbanisation & Effective & Effective \\
\hline $\begin{array}{c}\text { Rural } \\
\text { Landscape }\end{array}$ & Effective & Limited \\
\hline $\begin{array}{c}\text { Promote Public } \\
\text { Interest }\end{array}$ & Effective & Effective \\
\hline $\begin{array}{c}\text { Respond to } \\
\text { challenges }\end{array}$ & Effective & Effective \\
\hline $\begin{array}{c}\text { Practicality of } \\
\text { Measure }\end{array}$ & Limited & Possible \\
\hline
\end{tabular}

Recommendations: The both approach's are considered as favored option. To promote public interest and urbanization, both approaches are effective. In the case of rural landscape, the state wise approach would be effective, while the expansion of Chandigarh approach has limitations. On the other hand, practicality of implementation is possible in the later approach, while in former approach it is limited. The impact of these approach's will be experienced in or beyond the periphery if implemented successfully.

\section{CONCLUSION}

The data collected from the survey work clearly presents the picture of periphery of Chandigarh. More land encroachment activities around the periphery of Chandigarh is due to the economic opportunities and rapid increase in the prices of land. The objective of urban regulation policy is to recognize between urban and rural utilization, and it was well taken care of by periphery control act. Urban containment strategy alone could not control the kind of advancement inside or around the periphery, some extra techniques must also be introduced. State wise approach for urban control policy would ensure protective agriculture land utilization and the provincial lifestyle. While, the Union Territory expansion measure is to make changes in the periphery control act that could solve the issues previously originated.

\section{REFERENCES}

[1] Prakash, Aditya. "Concepts and principles for Haryana's new capital: beyond Corbusier (Chandigarh)." Environments 19, no. 2 (January 1988): 5-11

[2] Nelson, Arthur C., and Casey J. Dawkins. Urban Containment in the United States: History, models and techniques for regional and metropolitan growth management. Planning Advisory Service, Chicago: American Planning Association, 2004..
[3] Town and Country Planning Association. "Nothing Gained by Overcrowding! A Centenary Celebration and Re--exploration of Raymond Unwin's Pamphlet -- 'How the Garden City Type of Development May Benefit Both Owner and Occupier'." London: Town and Country Planning Association, April 2012.

[4] Easley, V. Gail. Staying Inside the Lines: Urban Growth Boundaries. Chicago: American Planning Association, 1992.

[5] Anthony, Jerry. "Do State Growth Management Regulations Reduce Sprawl?" Urban Affairs Review 39, no. 3 (January 2004): 376--397.

[6] DeGrove, John M., and Deborah A. Miness. Planning and Growth Management in the States. Cambridge, MA: Lincoln Institute of Land Policy, 1992.

[7] Jacobs, Allan B. "Observations on Chandigarh." Journal of the American Institute of Planners, November 2007.

[8] Chalana, Manish. "Centering the Periphery." Journal of Planning History. Forthcoming article, accessed 2014.

[9] Abigail Weber. "Within the Edge: A Revised approach to Urban Containment within Chandigarh Periphery" 2014.

[10] Chandigarh Administration. "Draft Chandigarh Master Plan 2031".

[11] Greater Mohali Area Development Authority. "Regional Plan 2008-2058." Plan.

[12] Haryana Urban Development Authority. Historical Background.

\section{AUTHORS PROFILE}

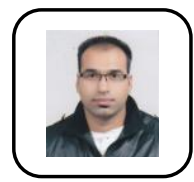

ANUJ SACHAR received his B-Tech degree in civil engineering in 2008 from Punjab Technical University, Jalandhar, M-Tech from RIMT University. Presently, he is working as Assistant Professor in Department of Civil Engineering RIMT University, Punjab, India.

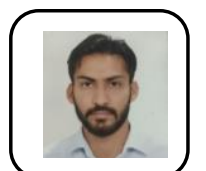

MANISH KAUSHAL received his B-Tech degree in civil engineering in 2011 from Punjab Technical University, Jalandhar, M-Tech from Punjab Technical University, Jalandhar in 2015.Presently, he is working as Assistant Professor in Department of Civil Engineering RIMT University, Punjab, India

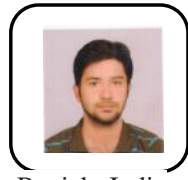

ASHISH KUMAR received his B-Tech degree in civil engineering in 2014 from Kurukshetra University, Haryana, M-Tech Kurukshetra University, Haryana, in 2016.Presently, he is working as Assistant Professor in Department of Civil Engineering RIMT University, Punjab, India

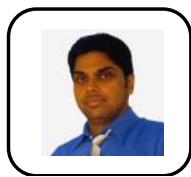

DR SANDEEP SINGLA received his B.Tech degree in civil engineering in 2001 from Punjab Technical University, Jalandhar M.Tech from Thapar Institute of Engineering \& Technology, Patiala in 2004 \& PhD degree from National Institute of Technology (NIT) Kurukshetra in 2018. Presently, he is working as Professor \& Head in Department of Civil Engineering, RIMT University, Punjab, India. He has published more than 60 papers in national and international journals/conferences. He has guided more than $30 \mathrm{M}$.Tech thesis. 